\title{
Study on the inhibiting factors of the activated sludge activity of hexavalent chromium based on the change of dissolved oxygen*
}

\author{
Wen-Yu Zhao ${ }^{1,2, a}$, Zheng Zhao ${ }^{1,2, \text { b }}$, Mei-Juan $\mathrm{Xu}^{3, \mathrm{c}, \dagger}$, \\ Yu-Fen Chen ${ }^{4}$ and Chao Feng ${ }^{1,2}$ \\ ${ }^{1}$ Guangxi Key Laboratory of Environmental Pollution Control Theory \\ and Technology, Guilin University of Technology, Guilin 541004, China; \\ ${ }^{2}$ Collaborative Innovation Center for Water Pollution Control \\ and Water Safety in Karst Area, Guilin University of Technology, \\ Guilin 541004, China \\ ${ }^{3}$ The college of Mechanical and Energy Engineering, \\ Ningbo Institute of Technology, Zhejiang University, \\ Ningbo, 315100, China \\ ${ }^{4}$ Fujian Huan'an Detection \& Evaluation Co. Ltd, \\ Xiamen 361000, China \\ ${ }^{a}$ E-mail: zhaowenyu@ glut.edu.cn, ${ }^{b}$ E-mail: 670536499@qq.com, \\ †, ${ }^{c}$-mail:xmj80@126.com
}

\begin{abstract}
Based on the effect of variation of dissolved oxygen on the oxygen uptake rate (our), To study the effect of $\mathrm{Cr}^{6+}$ on the performance of activated sludge under different factors (concentration, MLSS, HRT, temperature, $\mathrm{pH}$ ) by using activated sludge own activity. It has certain reference significance for the early warning and treatment of heavy metal in sewage plant. The results indicated that: (1) when the concentration of $\mathrm{Cr}^{6+}$ is less than $15 \mathrm{mg} / \mathrm{L}$, the inhibition rate increases gradually. When the concentration of $\mathrm{Cr}^{6+}$ is more than $15 \mathrm{mg} / \mathrm{L}$, the inhibition rate changes significantly. (2) Low concentration of MLSS is sensitive to heavy metal, high concentration of heavy metals can resist certain impact load. (3)The metabolism of the microbe which in the activated sludge would decrease the activity when the residence time extends. (4) The inhibitory effect of hexavalent chromium on activated sludge decreased with the increase of $\mathrm{pH}$, and the tolerance ability of activated sludge to hexavalent chromium is stronger under the alkaline condition.(5) In the higher temperature, the activated sludge has strong impact tolerance to the same concentration of heavy metals.
\end{abstract}

Keyword: Oxygen Uptake Rate (OUR); Hexavalent Chromium; Activated Sludge; Inhibiting Factor.

\footnotetext{
* This work is supported by the Guangxi Scientific Experiment Center of Mining, Metallurgy and Environment (KH2012ZD004); and by the Guangxi Talent Highland for Hazardous Waste Disposal Industrialization; and by the Colleges and Universities in Guangxi Province Science and Technology Research Project(No. 2013ZD032).
} 


\section{Introduction}

In recent years, caused by the heavy metal pollution accidents happen from time to time. The water get worse by the accidents and even not up to the discharge index of the sewage plant [1-4]. Because overload of heavy metal ion will impact on the sludge system, and the toxicity of the ion will seriously inhibit the bacteria and other microorganisms. Chromium ion widely exist in sewage treatment plants from ore processing, metal surface treatment, leather tanning and other industries. Chromium ions have a great influence on the environment; the toxicity of it is related to the valence state. The hexavalent chromium is 100 times more toxic than trivalent chromium, and it is easily absorbed by and accumulates in the body, which has a great impact on the human body and environment.

Due to $\mathrm{Cr}^{6+}$ has a strong impact on activated sludge and activated sludge system. With the increase of concentration, the inhibitory effect is enhanced on the activity of activated sludge and the COD removal rate of the system. The study on the influence of activated sludge by $\mathrm{Cr}^{6+}$ by Barth [5] found that it was found that whether single or compound copper, nickel and zinc, there was no significant effect on the efficiency of aerobic biological treatment in the concentration range of $10 \mathrm{mg} / \mathrm{L}$. While the study by Moore [6] found that the treatment efficiency was not affected significantly at the pilot scale of biological when $\mathrm{Cr}^{6+}$ at the concentration of $50 \mathrm{mg} / \mathrm{L}$, but not as good as $\mathrm{Cr}^{6+}$ at the concentration of $5 \mathrm{mg} / \mathrm{L}$. It can be seen that there are differences in the biological inhibition of the hexavalent chromium, and the range of inhibition concentration may be due to the different research objects.

In this paper, according to the effects of hexavalent chromium ions in different metal ions concentration, MLSS, HRT, PH, and temperature on activated sludge were studied by simulated experiments which based on the principle of microbial oxygen consumption rate (OUR).And the experiments also has determine the impact of various factors on the impact of activated sludge and certain reference significance for the early warning and treatment of heavy metal in sewage plant.

\section{Materials and Methods}

\subsection{Early warning device for heavy metal toxicity of activated sludge}

The warning device for heavy metal toxicity of activated sludge was shown in Figure 1 . 


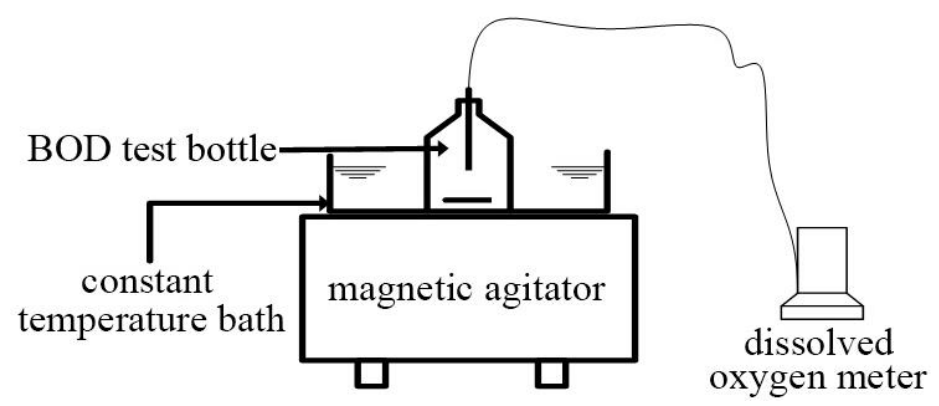

Fig. 1. Apparatus for measuring oxygen consumption rate of activated sludge.

The activated sludge and sewage derive from sludge in the aerobic phase and influent of sewage plant $(70 \%$ for domestic sewage, $30 \%$ for industrial wastewater, the $\mathrm{pH}$ value is about 7.5, MLSS is about $4000 \mathrm{mg} / \mathrm{L}$, first class national standard) which in Wuxi separately. And the sludge and sewage are configured into different concentrations as simulate wastewater of $\mathrm{Cr}^{6+}$.

\subsection{Research method}

The activated sludge and sewage were added in a certain proportion and mixed up by the magnetic mixer. Then the variables are under control by changing the sludge concentration MLSS and contact time (HRT). Heavy metal solutions are prepared by analytically pure reagent. DO is constantly monitored and the data is read every $2 \mathrm{~min}$ after the numerical value of dissolved oxygen meter settle down. Then calculate the aerobic rate (OUR) according to the correlation between Peak value and reference value and time.

Aerobic rate $(\mathrm{OUR})=\mathrm{OUR}=(\mathrm{DO} 1-\mathrm{DO} 2) / \mathrm{T}$

OUR — Specific oxygen consumption rate of activated sludge, mg $\left(\mathrm{O}_{2}\right) /$ $\left(\mathrm{L} ` \mathrm{~min}^{-1}\right)$;

DO1_ At the beginning of the BOD test bottle dissolved oxygen, $\mathrm{mg} / \mathrm{L}$

\section{Results and Discussion}

\subsection{The effect of activated sludge OUR on the concentration of different dissolved oxygen ions}

In the case of low concentration MLSS, the sludge is sensitive to heavy metals. The concentration of activated sludge (MLSS) put up as $500 \mathrm{mg} / \mathrm{L}$ to simulation of different concentrations of $\mathrm{Cr}^{6+}$. Determine the rate of oxygen consumption in the condition that the contact time (HRT) is $10 \mathrm{~min}$ and the chromium ion concentration is $(0,5,10,15,20,40) \mathrm{mg} / \mathrm{L}$ separately. The results are shown in Figure 2 . 


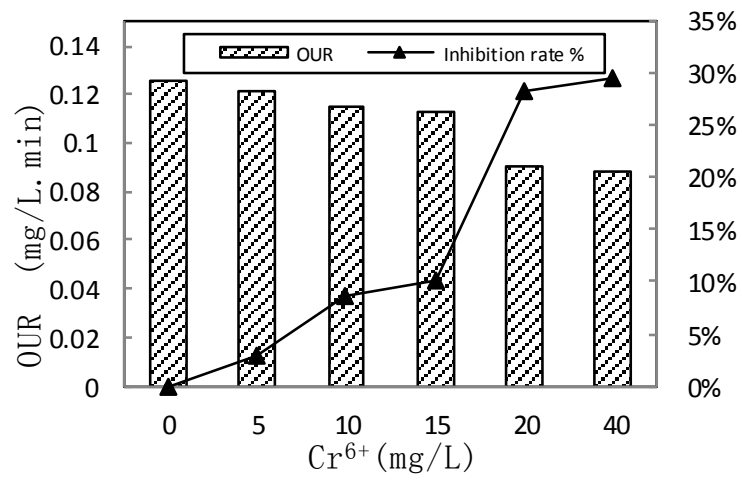

Fig. 2. Effect of OUR on the concentration of under different concentrations of hexavalent chromium.

As shown in Figure 2, the oxygen consumption rate of activated sludge decreased with the increase of $\mathrm{Cr}^{6+}$ ion concentration in the wastewater. The inhibition rate is gradually increased and the rate is relatively slow when the concentration of $\mathrm{Cr}^{6+}$ ion was less than $15 \mathrm{mg} / \mathrm{L}$ and the inhibition rate changes significantly when the concentration of $\mathrm{Cr}^{6+}$ ion is more than $15 \mathrm{mg} / \mathrm{L}$.

\subsection{The effect of on activated sludge OUR under different MLSS by $\mathrm{Cr}^{6+}$}

The concentration of MLSS can reflect the biomass of activated sludge, and it is the key factor of influence. The higher the concentration of MLSS, the stronger toxic and hazardous substances buffer capacity and the ability to withstand. On the contrary, the more sensitive [7].Two groups of experiments with activated sludge concentration was $3462 \mathrm{mg} / \mathrm{L}$, the influent COD concentration of sewage treatment plant was $171 \mathrm{mg} / \mathrm{L}, 21^{\circ}, \mathrm{pH} 7.2$, and the slurry ratio is $1: 3$ and $1: 4$. The results are shown in Figure 3. (The 1, 2 belonged to the first group and the two groups of experiments).

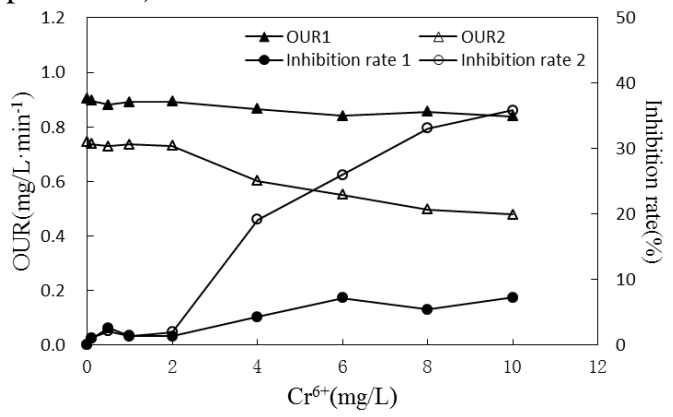

Fig. 3. The effect of hexavalent chromium on activated sludge OUR Under different MLSS condition. 
From the above experimental results can be drawn as follows: there was a significant difference in the inhibition of activated sludge OUR by $\mathrm{Cr}^{6+}$, which is sensitive to heavy metals on low MLSS and performance for the OUR change, under different MLSS concentration conditions.

\subsection{The effect of on activated sludge OUR under different HRT by Cr6+}

Hydraulic retention time (HRT) is one of the important parameters of activated sludge, from which heavy metals on activated sludge inhibition different. Experiments were carried out at Cr6+ were $5 \mathrm{mg} / \mathrm{L}$ and $10 \mathrm{mg} / \mathrm{L}$, MLSS were 500 $\mathrm{mg} / \mathrm{L}, \mathrm{HRT}$ were and $0,20,40,60 \mathrm{~min}$ respectively. The inhibition rate of different reaction time was determined by using chromium as an example. Results are shown in Figure 4.

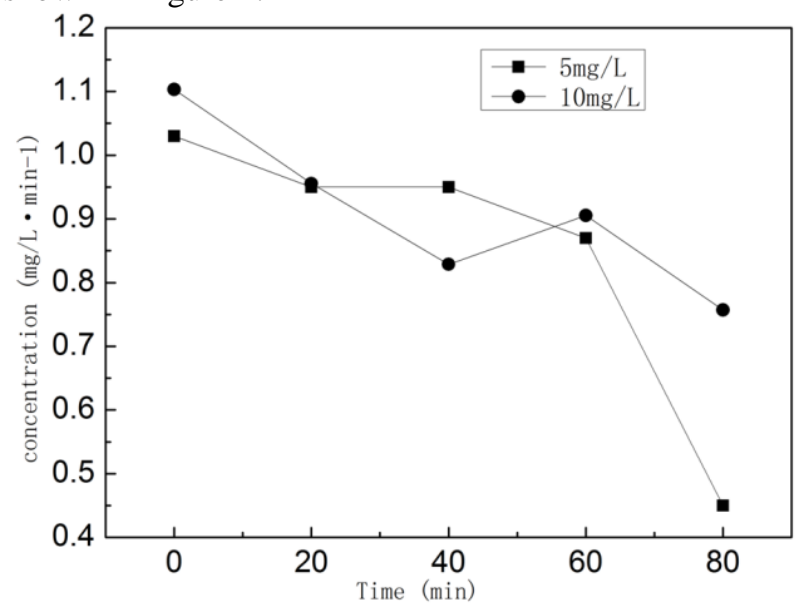

Fig. 4. The effect of on activated sludge OUR under different $\mathrm{HRT}$ by $\mathrm{Cr}^{6+}$

From the experimental results can be drawn as follows: with the increase of HRT, the aerobic rate of activated sludge is gradually reduced. The normal system of heavy metals mainly by destroying the enzymes of the microor ganisms, with the increase of reaction time, the metabolic pathway of microorganism is gradually being inhibited, which leads to the decrease of the function of activated sludge [8-9], and with the increase of the concentration of metal, the inhibitory effect was enhanced, for which the higher $\mathrm{Cr}^{6+}$, the faster rate of aerobic reduce reason.

\subsection{The effect of on activated sludge OUR under different $\mathrm{pH}$ by $\mathrm{Cr}^{6+}$}

The presence of heavy metals was influenced by different $\mathrm{pH}$ forms, which including four aspects of valence state, combined state, bound state, structure 
state[10] and the toxicity and environmental behavior may be different in one or several aspects of the form. The low or high $\mathrm{pH}$ will affect the activated sludge microbial extracellular enzymes and exist in cytoplasm and cell wall of enzyme catalysis, and microorganisms on nutrient absorption, and affect its activity.

To investigate the inhibition of $\mathrm{Cr}^{6+}$ on activated sludge under different $\mathrm{pH}$ conditions, which experiments activated sludge concentration was $3508 \mathrm{mg} / \mathrm{L}$, the influent COD was $188 \mathrm{mg} / \mathrm{L}$, slurry ratio is $1: 3$, and the ion concentration in the influent was $5 \mathrm{mg} / \mathrm{L}$. The experimental results are shown in Figure 5.

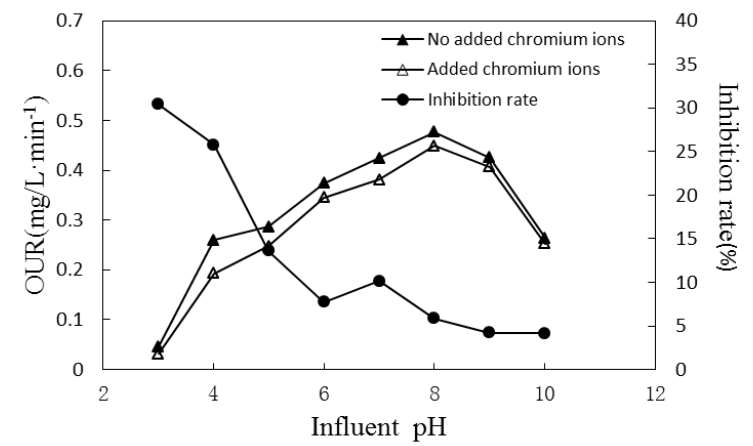

Fig. 5. The effect of on activated sludge OUR under different $\mathrm{pH}$ by $\mathrm{Cr}^{6+}$

From the above experimental results can be drawn as follows:(1)PH had a significant effect on the sludge activity OUR, with the increase of $\mathrm{pH}$ first enhanced and then weakened, OUR maximum value when influent $\mathrm{pH}$ was 8 , mixed solution $\mathrm{pH}$ was 7.69 , so activated sludge activity was the strongest. (2)The OUR was significantly smaller the activated sludge with the addition of $\mathrm{Cr}^{6+}$ to not add under the same $\mathrm{pH}$ condition. (3)The inhibitory effect of six chromium on activated sludge decreased with the increase of $\mathrm{pH}$, which proved tolerant ability of activated sludge to six chromium, is strong under alkaline conditions.

\subsection{The effect of on activated sludge OUR under different temperature by $\mathrm{Cr}^{6+}$}

The toxicity of general metal pollutants increased with the increase of temperature [11]. The temperature is one of the key factors that affect the sludge activity, and particle size, density, surface charge and microbial activity was also found. The effects of heavy metals on the activity of activated sludge under different temperature conditions were studied with six chromium and $\mathrm{Cu}^{2+}$ as examples, which experiments temperature was $18^{\circ} \mathrm{C}$ and $25^{\circ} \mathrm{C}$, the metal ion concentration in the influent was $5 \mathrm{mg} / \mathrm{L}$. activated sludge concentration was 
$3508 \mathrm{mg} / \mathrm{L}$, the influent COD was $196 \mathrm{mg} / \mathrm{L}$. The experimental results are shown in Figure 6.

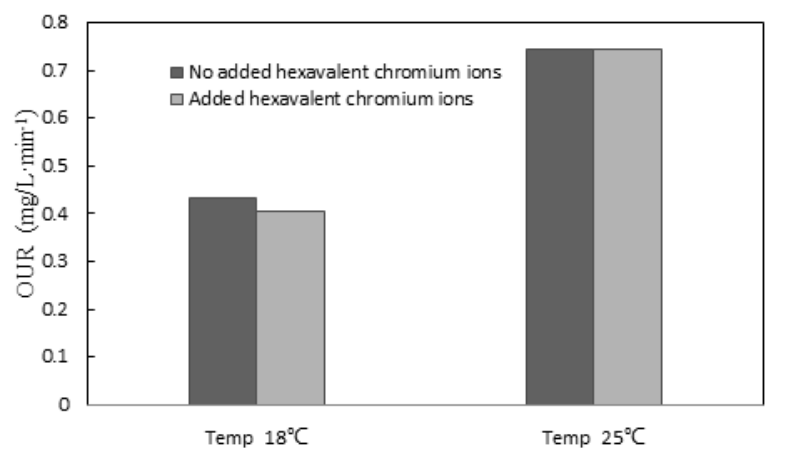

Fig. 6. Effect of heavy metals on activated OUR of activated sludge under different temperature

From the above experimental results can be drawn as follows: the inhibition rate of $\mathrm{Cr}^{6+}$ to activated sludge OUR was $6 \%$ under the condition of $18^{\circ} \mathrm{C}$, and no significant inhibition was produced under the condition of $25^{\circ} \mathrm{C}$. Activated sludge on the same concentration of heavy metals has a strong impact resistance under the conditions of higher temperature and stronger sludge activity. On the contrary, the impact resistance is relatively poor, which susceptible to heavy metals.

\section{Conclusions}

1. The sewage plant sludge oxygen uptake rate (OUR) with wastewater $\mathrm{Cr} 6+$ ion concentration decreases when $\mathrm{Cr}^{6+}$ ion concentration is less than $15 \mathrm{mg} / \mathrm{L}$ inhibition rate gradually increased, the rate is relatively slow, when $\mathrm{Cr}^{6+}$ ion concentration greater than $15 \mathrm{mg} / \mathrm{L}$, the inhibition rate of change significantly.

2. The inhibition of $\mathrm{Cr}^{6+}$ on activated sludge OUR has a significant difference under different MLSS concentration. The MLSS concentration is low in the activated sludge, which is sensitive to heavy metals, and the performance of OUR is large.

3. With the hydraulic retention time (HRT) growth rate of aerobic activated sludge decreases, the normal metabolic pathways of heavy metals destroying microbes adjuvant enzymes, microbes gradually being inhibited, causing the function of activated sludge reduce.

4. The inhibitory effect of $\mathrm{Cr}^{6+}$ on activated sludge decreased with the increase of $\mathrm{pH}$, and the tolerance ability of activated sludge to $\mathrm{Cr}^{6+}$ was stronger under alkaline condition. In the influent $\mathrm{pH}$ is 8 , the mixed liquid $\mathrm{pH}$ is 7.69 to reach the maximum value of OUR, the activated sludge activity is the strongest.

5. The activated sludge had strong impact resistance to the same concentration of heavy metals under the higher temperature. On the contrary, the 
impact resistance is relatively poor; the sludge activity is susceptible to heavy metals.

\section{References}

1. S.A. Ong, and P.E. Lim, and C.E. Seng, Effects of $\mathrm{Cu}$ (II) and Cd (II) on the performance of sequencing batch reactor treatment system. Process Biochemistry, (Oita, Japan, 2005)

2. A. Nicolau, and M.J. Mrtins, and M. Mota, Effect of copper in the protistan community of activ ated sludge. Chemosphere, (Braga, Portugal, 2005)

3. I.J. Maziersk, Effect of chromiun(VI) on the growth rate of activated sludge bacteria. Water Research, (Zabrze, Poland, 1995).

4. V.K. Gupta, and A. Nayak, and S. Agarwal, Bioadsorbents for remediation of heavy metals: Current status and their future prospects. Environmental Engineering Research, (Korea, 2015).

5. E.F. Barth, and M.G. Ettinger, and B. Salotto, and G.N. Mcdermott, Summary report on the effects of heavy metals on the biological treatment process. Water air and soil pollution, (Cincinnati, America, 1965).

6. W.A. Moore, and G.N. McDermott, and M.A. Post, and M.B. Ettenger, Effects of chromium on the activated sludge process. Water air and soil pollution, (1961).

7. S.S Ahluwalia, and D. Goyal, Microbial and plant derived biomass for removal of heavy metals from wastewater. Bioresource technology, (Punjab, India, 2007).

8. Y.P. Wang, and J.Y. Shi, and H. Wang, et al., The influence of soil heavy metals pollution on soil microbial biomass enzyme activity, and community composition near a cooper smelter. Ecotoxicology and Environmental Safety, (Hangzhou, China, 2007).

9. H.M. Belen, and J.A. Carreira, and R.R. Garcia, et al., Soil misture pre-treatment effects on enzyme activities on enzyme activities as indicators of heavy metal-contaminated and reclaimed soils. Soil. Biol. Biochem, ( Jaén, Spain 2004).

10. M. H. Feng, and X.Q. Shan, and S. Z. Zhang, et al., A comparison of the rhizosphere-based method with DTPA, EDTA, CaCl2, and NaNO3 extraction methods for predict ion of bioavailability of metals in soil to barley. Environmental Pollution, (Beijing, China, 2005).

11. I.V. Zykova, and V.P. Panov, and T.G. Makashova, et al., Fundamental Aspects of Heavy Metal Absorption by Activated - Sludge Microorganisms. Russian Journal of Applied Chemistry, (Petersburg, Russia, 2002.) 